\title{
Research on mechanical-hydraulic system simulation method for multi-control multiway valve
}

\author{
Naixin Xiao ${ }^{1}$, Lei $\mathrm{Xu}^{1 *}$, Li-ping Zhang ${ }^{1}$, Da-shuang $\mathrm{Li}^{1}$ \\ ${ }^{1}$ School of Mechanical Engineering, Sichuan University, Chengdu, Sichuan, China
}

\begin{abstract}
Based on the control principle and flow distribution characteristics of the electro-hydraulic proportional load-sensitive multiway valve in an excavator, a system simulation model is established in AMEsim. After proving the accuracy of this model by comparing simulation results with theoretical results for various flow distribution characteristics under saturated and unsaturated conditions, this model is used to study the effect of three-way valve preload on the multiway valve system to prove that the simulation method can evaluate the influence of design parameters on the multiway valve system and then guide the design of multiway valves.
\end{abstract}

\section{Introduction}

Multiway valve is a highly integrated hydraulic control component, which can simultaneously control multiple actuators with a pump in a hydraulic control system. Multiway valve is widely used in mobile multi-actuator hydraulic equipment.

However, multi-control multiway valve has complex structure and internal control, and it is highly integrated. Therefore, it is difficult to evaluate the effect of multiway valve design parameters on system performance.

A lot of researches on multiway valve have been carried out. Ref. [6] focused on multiway valve throttling coupling in the process of multiway valve reversing, and used particle swarm algorithm to optimize the structural topology design of valve port throttle groove. Zhang et.al.[7] derived the flow area formulas of two multi-way valve spool valve ports to study the effect of the valve port type on the flow control characteristics of the multi-way valve, and finally verified it through flow field simulation. Ref.[8] used Adams and AMEsim co-simulation method to study the dynamic characteristics of LUDV (Load pressure-independent flow distribution) system of multiway valve. Ref.[9] provided a method for condition monitoring and online fault detection with proportional hydraulic valve to help controller compensate for the fault behavior. Li et.al.[10] aimed at the parametric uncertainties and unknown disturbance in hydraulic system, by designing controllers and observers to improve the performance of hydraulic system. The above references mainly focused on three topics: the local structure of multiway valve, the system performance based on co-simulation method, and the control of hydraulic system, but these references did not consider the design parameter evaluation of multiway valve during the design period.

This paper aims at an electro-hydraulic proportional load-sensitive multiway valve, which is a complex hydraulic component with multiple controls. Firstly, the control principle and the flow distribution characteristics are analyzed. Then, a simulation model based on the multiway valve in an excavator is established in AMEsim. To verify the accuracy of the model, theoretical analyses and simulation results are compared in the flow distribution characteristics under saturated and unsaturated conditions. Finally, this model is used to study the influence of the spring preload of the three-way flow valve on the system. This method provides a reference for the design of multi-control valves.

\section{Control principle and flow distribution characteristics}

\subsection{Control principle}

Figure1 is the cross-sectional view of the reversing body of the multiway valve. This multiway valve has three control modes: (1) Handle control capable of emergency operation though handle control block1. (2) Electro-hydraulic proportional control though dual proportional electromagnetic integrated control block6. (3) Load sensitive control. 


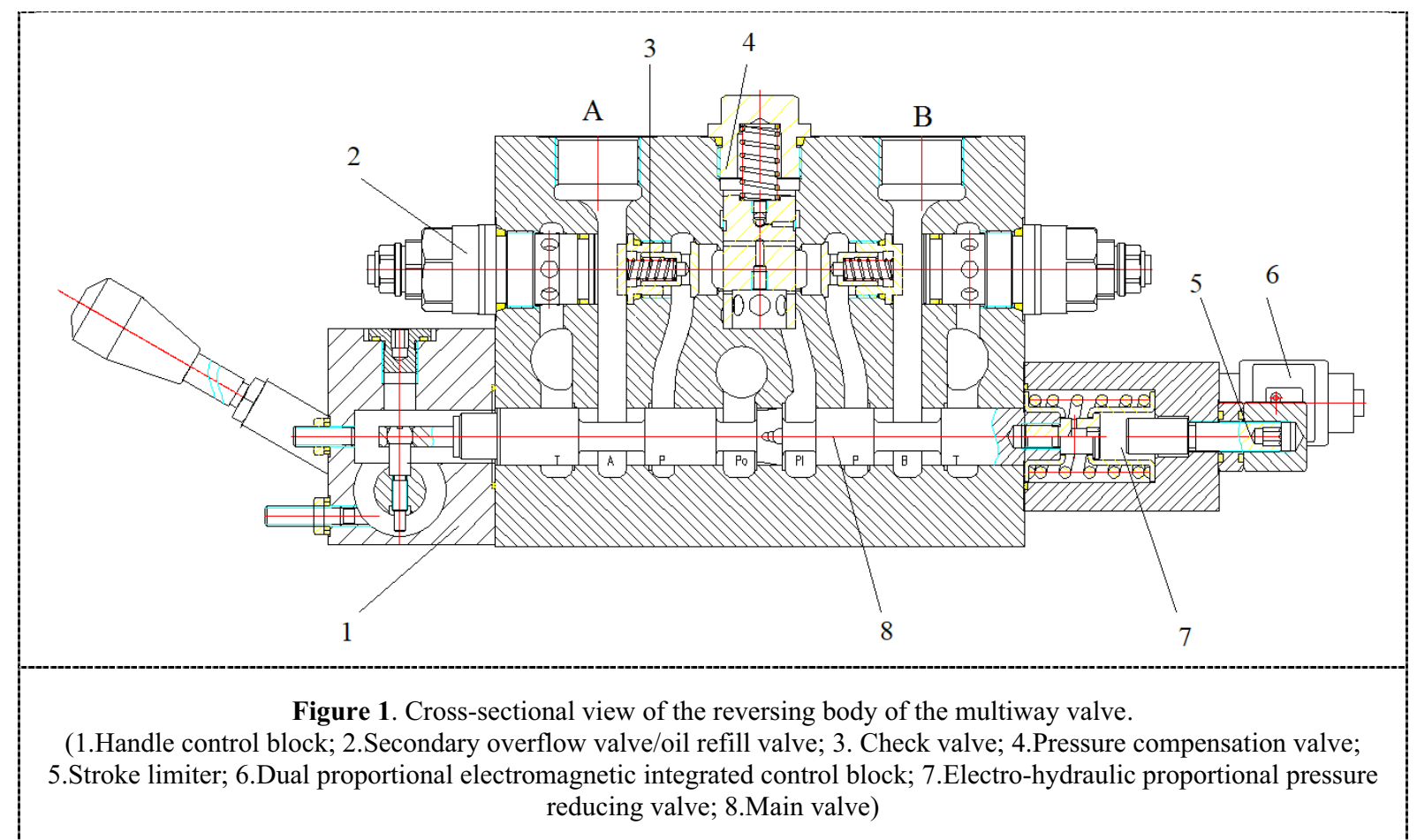

Figure 2 shows a schematic diagram of the multiway valve of three groups. In the diagram, $A_{i}$ and $B_{i}$ are the inlet and the outlet of the $i$ th actuator, respectively,

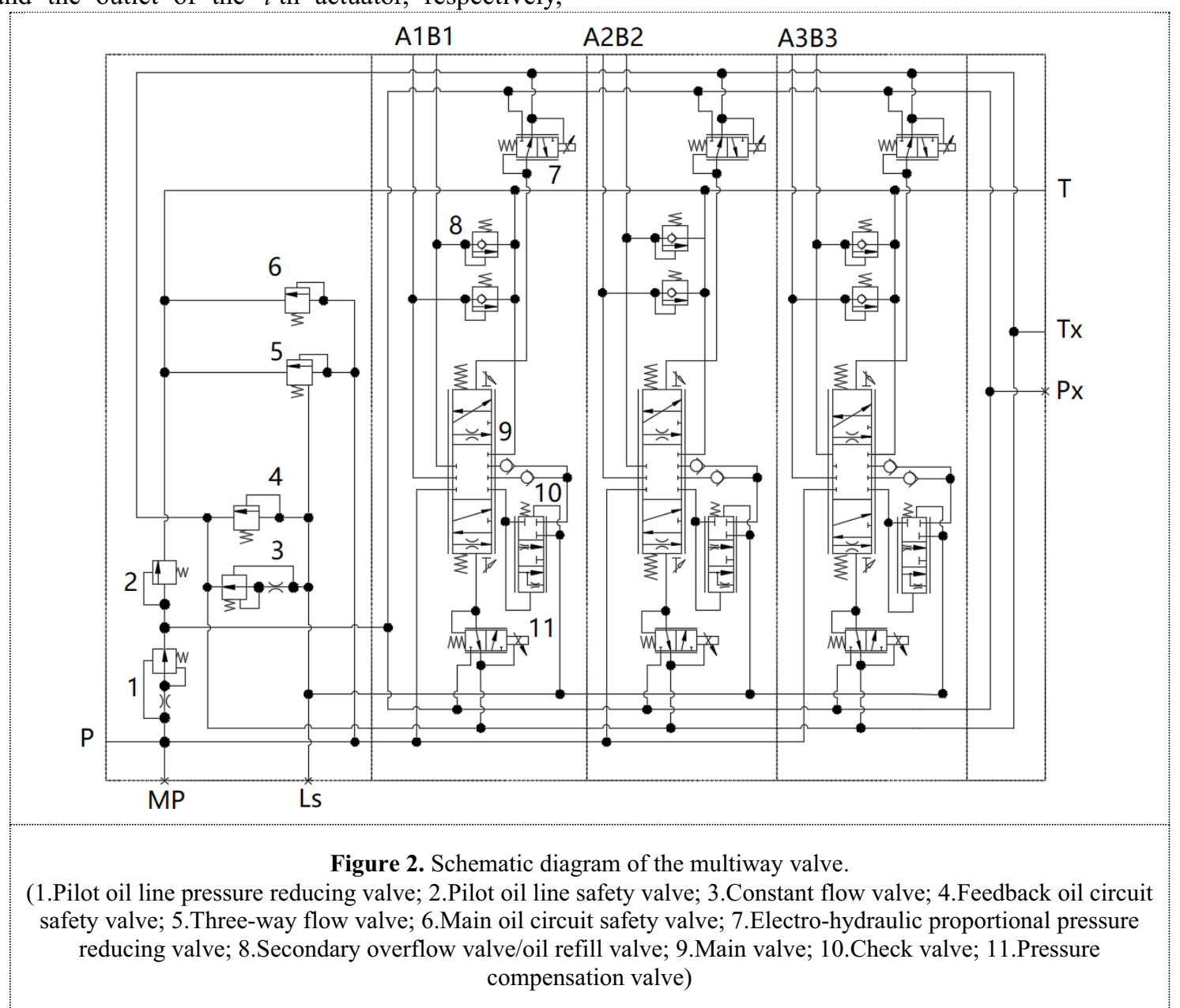

This paper uses a quantitative pump system for research. Its load-sensitive control principle is: the load pressure LS is introduced into the three-way flow valve where $i=1,2,3$. 
of the three-way flow valve realizes the diversion of excess flow of the system, and ensures that the flow provided by the system to the actuator matches the flow required by the load.

\subsection{Flow distribution characteristics}

Based on the electro-hydraulic proportional load-sensitive multiway valve, the flow distribution principle of the quantitative pump system in an excavator is as follows:

The pressure difference at the valve port of the main valve is:

$$
P_{s}-P_{1}=P_{s}-P_{2}=P_{s}-P_{3}=P_{s}-\left(\frac{F_{0}}{A_{c 0}}+P_{L s}\right)
$$

Where $P_{s}$ is the pump outlet pressure; $P_{1}, P_{2}$ and $P_{3}$ are the inlet pressures of the three pressure compensation valves; $F_{0}$ is the spring preload of the pressure compensation valves; $A_{c 0}$ is the end surface compression area of the compensation valve spool; $P_{L s}$ is the LS pressure.

The demand flow of each actuator is:

$$
q_{i}=C_{q} W_{i} X_{i}\left[\frac{2}{\rho}\left(P_{s}-\frac{F_{0}}{A_{c 0}}-P_{L s}\right)\right]^{1 / 2}=C_{q} f\left(U_{i}\right)\left[\frac{2}{\rho}\left(P_{s}-\frac{F_{0}}{A_{c 0}}-P_{L s}\right)\right]^{1 / 2}
$$

where $i=1,2,3$.

Then, the total flow is given by formula (3):

$$
q_{t}=q_{1}+q_{2}+q_{3}+q_{f}=q_{s}+q_{f}
$$

Where $q_{i}$ is the demand flow of the $i$ th actuator; $q_{f}$ is the overflow of the three-way flow valve; $C_{q}$ is the flow coefficient; $W_{i}$ and $X_{i}$ represent the flow area gradient and the opening degree of the $i$ th main valve respectively; $U_{i}$ is the operating electrical signal of the $i$ th actuator; $q_{s}$ is the total demand flow of actuators; $q_{t}$ is the pump outlet flow.

Therefore, when $q_{f}=0$, the flow distribution relationship among actuators is as follows:

$$
\frac{q_{i}}{q_{s}}=\frac{C_{q} W_{i} X_{i}\left[\frac{2}{\rho}\left(P_{s}-\frac{F_{0}}{A_{c 0}}-P_{L s}\right)\right]^{1 / 2}}{C_{q} W_{i}\left(X_{1}+X_{2}+X_{3}\right)\left[\frac{2}{\rho}\left(P_{s}-\frac{F_{0}}{A_{c 0}}-P_{L s}\right)\right]^{1 / 2}}=\frac{W_{i} X_{i}}{\sum_{k=1}^{3} W_{k} X_{k}}
$$

The pump outlet pressure $P_{s}$ and the system pressure margin $\Delta P$ can be derived:

$$
\begin{gathered}
P_{s}=P_{L s}+\frac{F_{0}}{A_{c 0}}+\frac{1}{C_{q}^{2}} \frac{\rho}{2}\left(\frac{q_{t}-q_{f}}{\sum_{k=1}^{3} W_{k} X_{k}}\right)^{2}=P_{L s}+\frac{F_{0}}{A_{c 0}}+\frac{1}{C_{q}^{2}} \frac{\rho}{2}\left(\frac{q_{s}}{\sum_{k=1}^{3} W_{k} X_{k}}\right)^{2} \\
\Delta P=P_{s}-P_{i}=\frac{1}{C_{q}^{2}} \frac{\rho}{2}\left(\frac{q_{s}}{\sum_{k=1}^{3} W_{k} X_{k}}\right)^{2} \quad i=1,2,3
\end{gathered}
$$

It can be seen from the formulas that, in the quantitative pump system, the multiway valve system can be influenced by many parameters, such as each actuator corresponds to the flow area of the main valve, the overflow flow of the three-way flow valve, the load sensitive pressure, the pressure compensation valve spring preload, total flow required by the actuator and so on. The selection of their values determines the working performance of the multiway valve. Therefore, it is necessary to find a suitable way to research the effect of these parameters.

\section{Establishing a mechanical-hydraulic system simulation model}

In this paper, based on the above control principle and flow distribution characteristics, a mechanical-hydraulic system simulation model is established by using the HCD library, the signal and control library, the planar mechanical library and the hydraulic library in AMEsim.

The parameters of three actuators of this excavator are different, which needs load-sensitive control mode work. (Their values of inner diameter, rod diameters and stroke are respectively $115 \mathrm{~mm} / 65 \mathrm{~mm} / 800 \mathrm{~mm}, 95 \mathrm{~mm} / 60 \mathrm{~mm} / 750 \mathrm{~mm}$ and $85 \mathrm{~mm} / 55 \mathrm{~mm} / 720 \mathrm{~mm}$ ) And then, the other initial parameters in table 1 can be entered.

Table 1. Part of main parameters of the system.

\begin{tabular}{|l|c|c|}
\hline \multicolumn{1}{|c|}{ Name } & Variables and units & Value \\
\hline Motor speed & $\mathrm{N} /(\mathrm{r} / \mathrm{min})$ & 1500 \\
\hline Displacement of the fixed pump & $\mathrm{V} /(\mathrm{cc} / \mathrm{rec})$ & 80 \\
\hline Temperature of the fluid & $\theta /\left({ }^{\circ} \mathrm{C}\right)$ & 40 \\
\hline Density of the fluid & $\rho /\left(\mathrm{g} / \mathrm{m}^{3}\right)$ & 850 \\
\hline Preload of the main valve spring & $\mathrm{Fp} /(\mathrm{N})$ & 92 \\
\hline Stiffness coefficient of the main valve spring & $\mathrm{K} /(\mathrm{N} / \mathrm{mm})$ & 30 \\
\hline
\end{tabular}

The AMEsim model of a single reversing body of the multiway valve is shown in figure 3 . Because the components of the multiway valve reversing body only different in specific parameters, a triple combined simulation module can be created and packaged as a super module based on the single reversing body model, and named "triple branch reversing body". According to the working laws of Hitachi ZX70-5A medium excavator, the kinematic pairs and constraint relationships among mechanical structures are determined. Therefore, a two-dimensional model of the excavator can be obtained by using the planar machine library, as shown in figure 4 . Finally, a visualized mechanical-hydraulic system 
simulation model based on the electro-hydraulic excavator is established, as shown in figure 5. proportional load-sensitive multiway valve in an

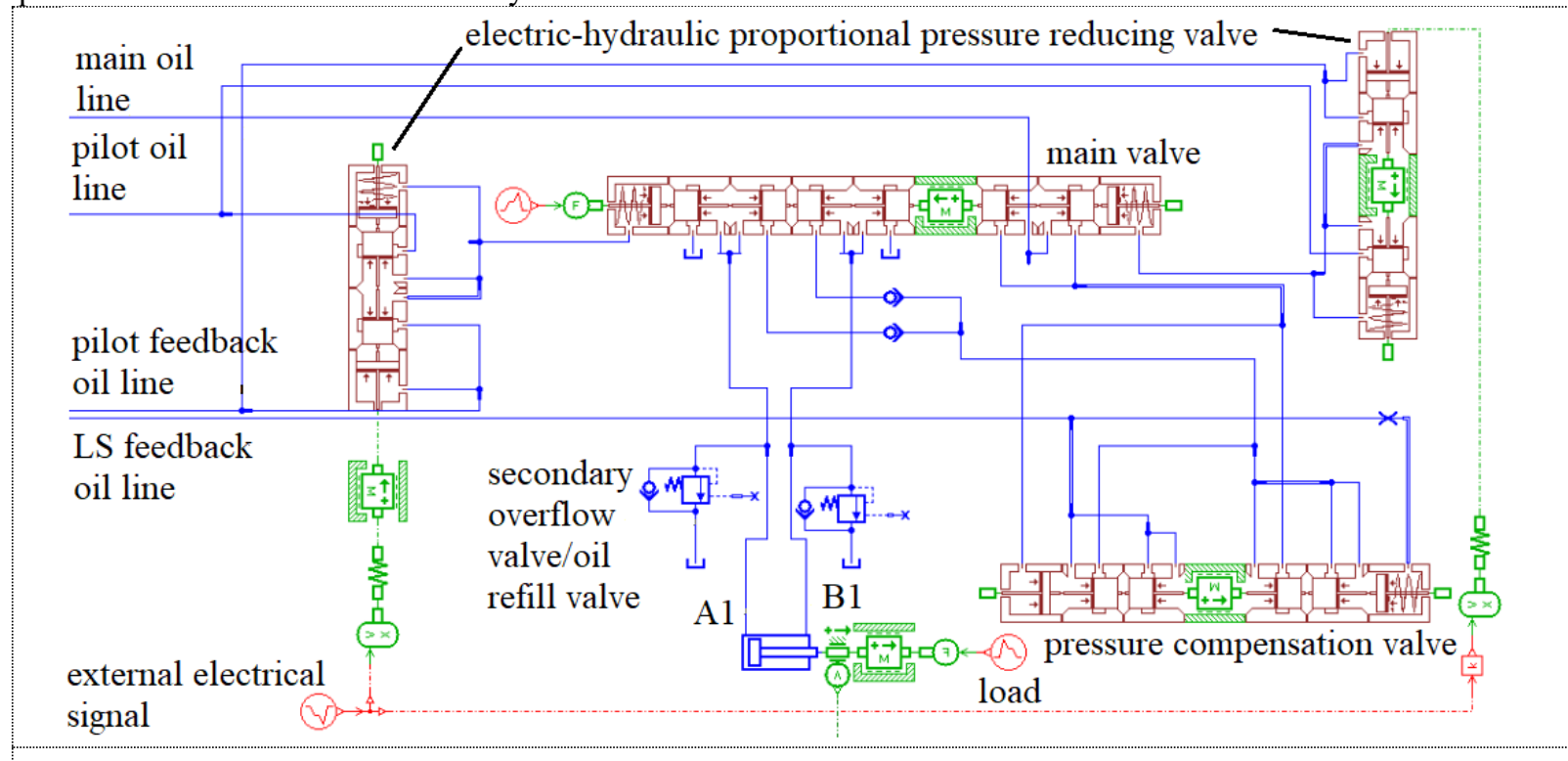

Figure 3. AMEsim hydraulic model of the reversing body of the multiway valve.

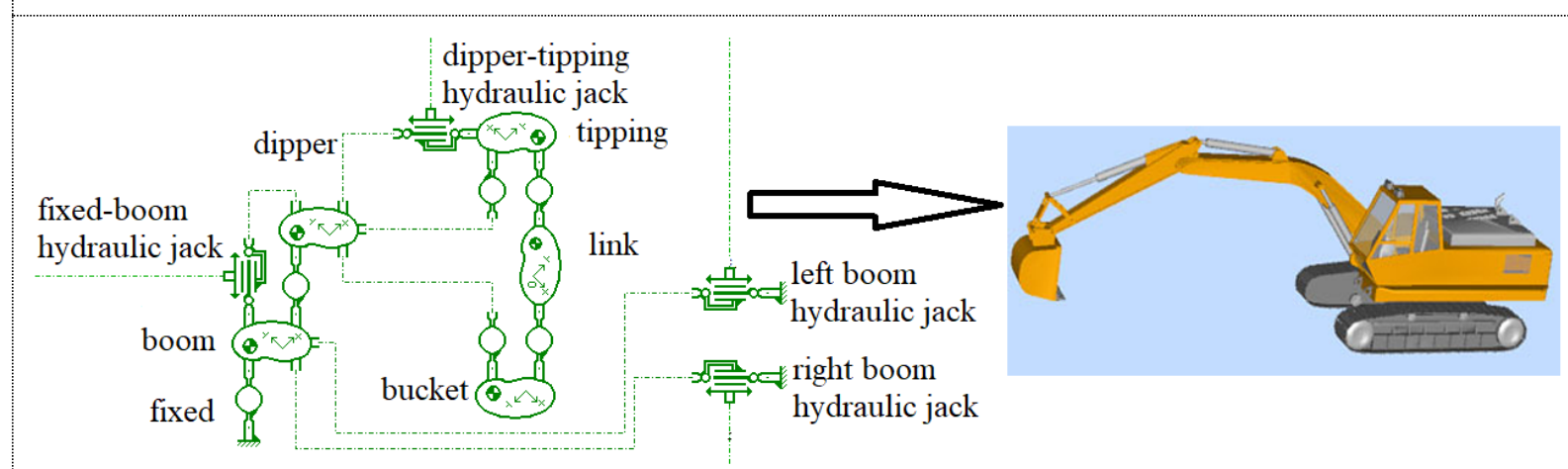

Figure 4. Two-dimensional model and three-dimensional visualized model of a hydraulic excavator. 


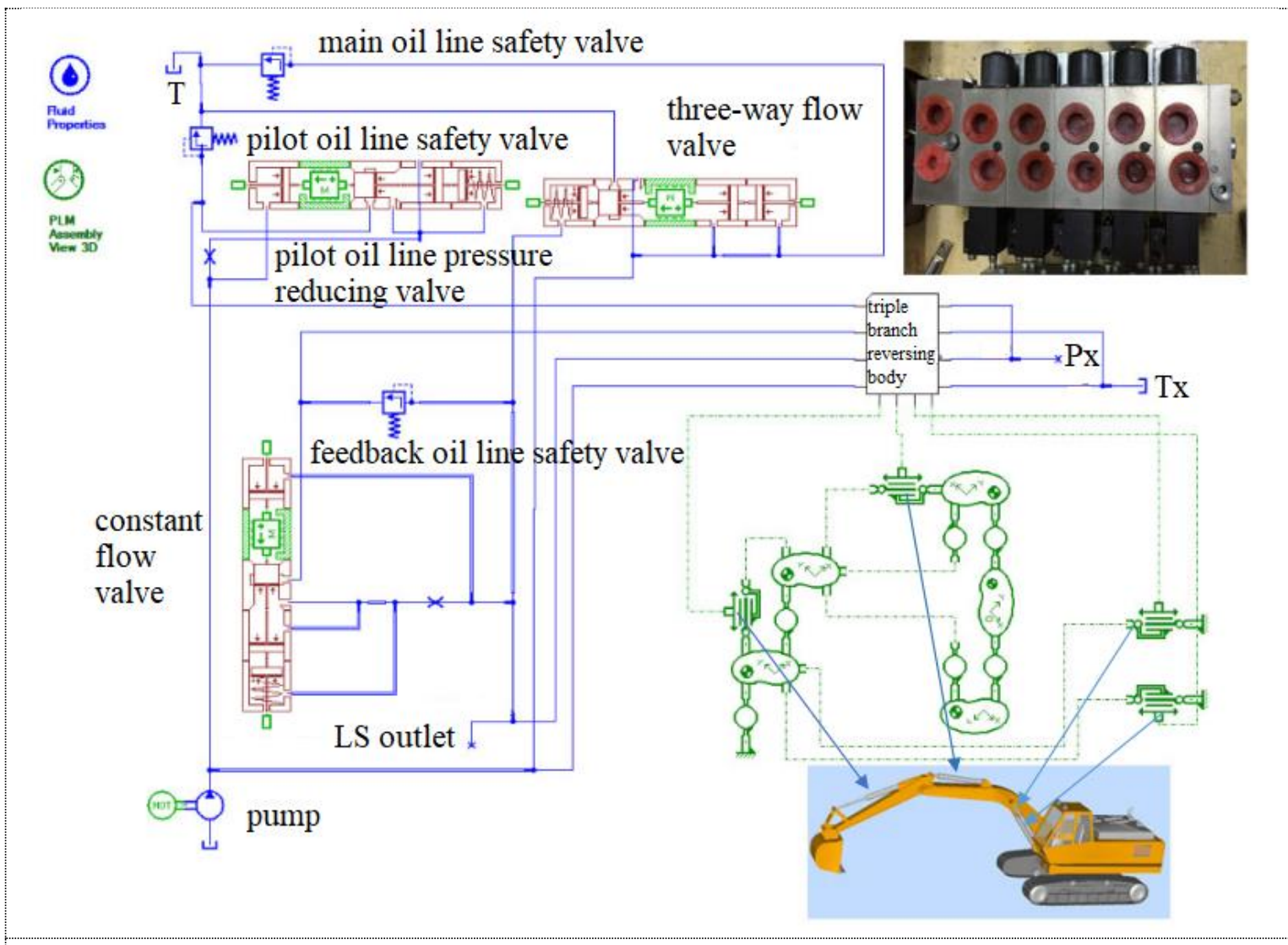

Figure 5. The comprehensive mechanical-hydraulic system simulation model.

\section{Verifying the accuracy of simulation model}

The flow sharing distribution characteristics of the multiway valve can realize normal operation between different load mechanisms under saturated flow condition without interference. In order to verify the correctness of the model,

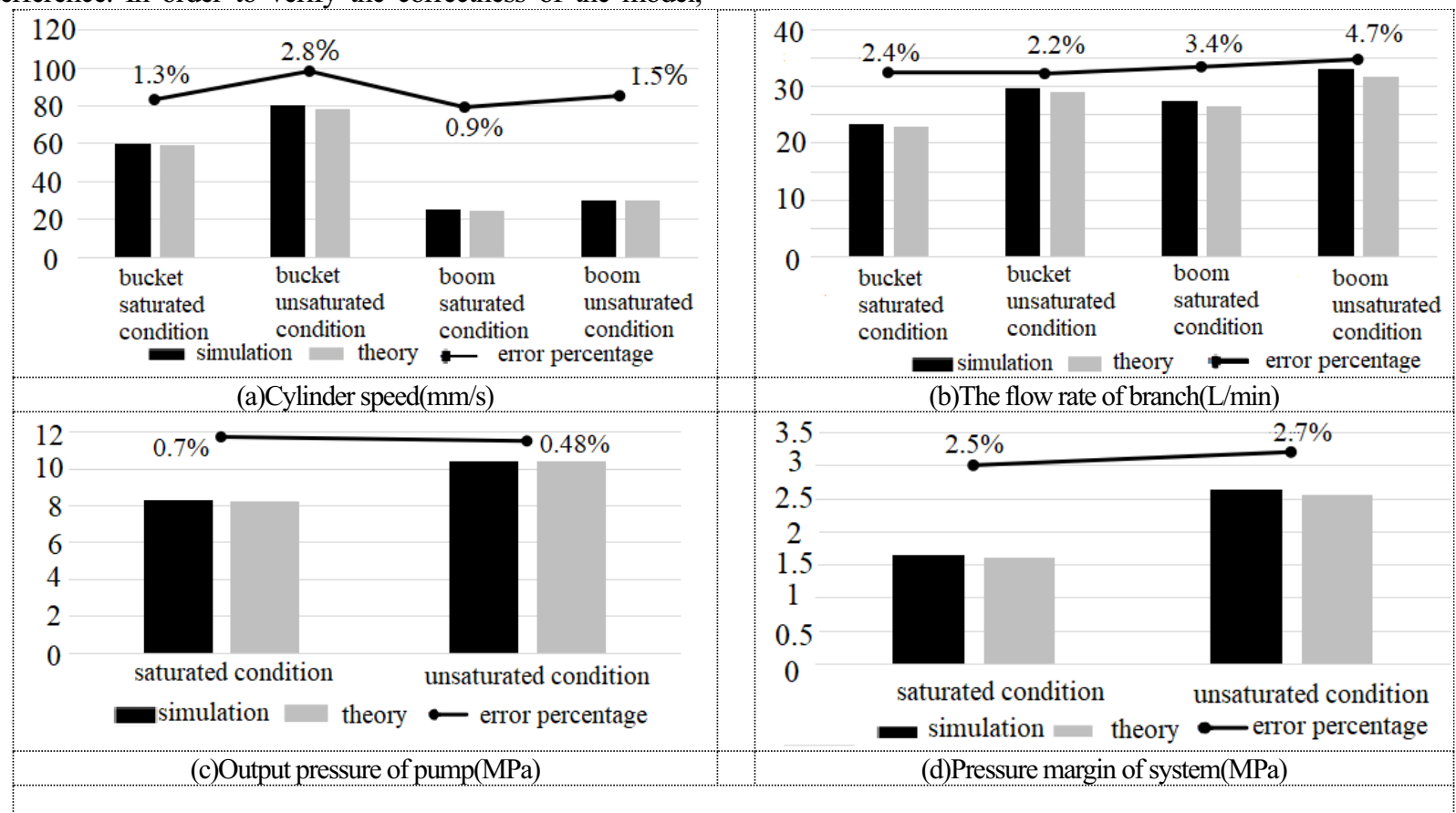

Figure 6. Simulation results, theoretical results and error percentage under saturated and unsaturated conditions compare the theoretical value and simulation value of the flow when the tractor's bucket and boom complete the contraction combined action under the flow saturated and unsaturated conditions. Figure 6 shows a comparison of the flow distribution characteristics under saturated and flow unsaturated flow conditions. The error percentage ranges from $0.48 \%$ to $4.70 \%$, which proves the accuracy of this system model. 


\section{Model application example}

The model established in this paper can be used to determine the influence of the parameters on the system in the design processing.

When studying the effect of the spring preload of the three-way flow valve on the system, the simulation model can be used to observe the effect of multiple sets of preload values on the system by the batch processing method. The parameter settings are shown in Figure 7, and the simulation results are shown in Figure 8.

\begin{tabular}{|c|c|c|c|c|c|c|c|c|c|c|c|}
\hline Name & Unit & Set 1 & Set 2 & Set 3 & Set 4 & Set 5 & Set 6 & Set 7 & Set 8 & Set 9 & Set 10 \\
\hline$\checkmark$ f0_bap3_6 & $\mathrm{N}$ & 50 & 100 & 150 & 200 & 250 & 300 & 350 & 400 & 450 & 500 \\
\hline
\end{tabular}

Figure 7. The parameter settings of spring preload of the three-way flow valve.
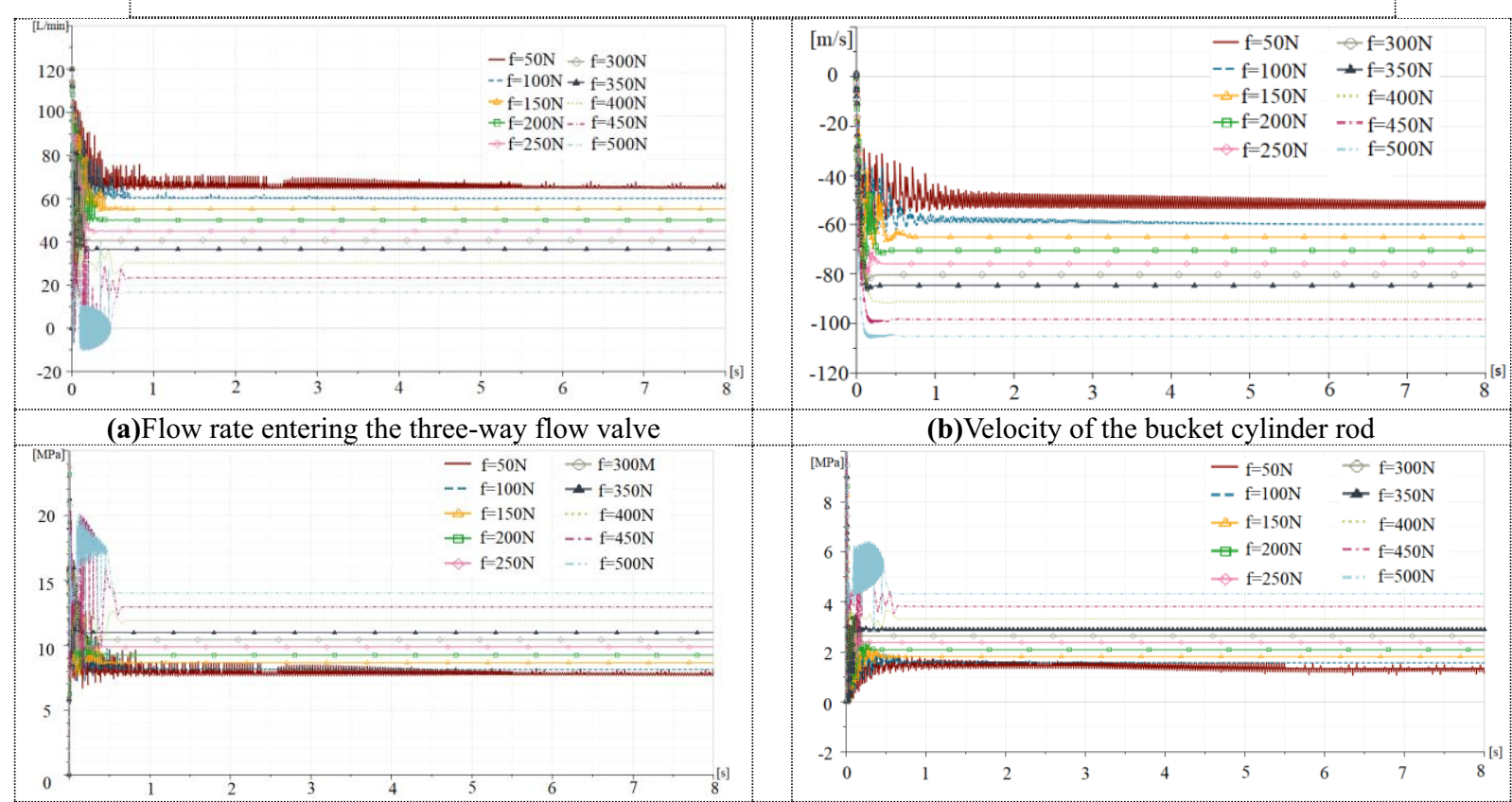

(c)Output pressure of pump

(b) Velocity of the bucket cylinder rod

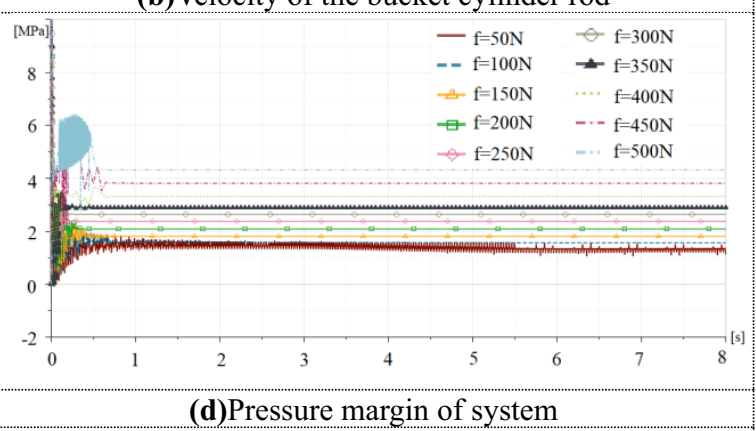

Figure 8. Effect of the three-way flow valve spring preload on system.

According to the figure 8 , when the preload changes from $50 \mathrm{~N}$ to $500 \mathrm{~N}$, the overflow of the three-way flow valve decreases, while the flow entering load branch, the speed of actuators, pressure margin and pump outlet pressure all increase accordingly.

The system goes through the initial attenuated oscillation stage, the intermediate transition stage and the late oscillation enhancement stage. The results of the flow rate entering the three-way flow valve are disassembled according to three states, as shown in figure 9 . In the first stage, the system is in an attenuated oscillation state, and it takes too long for the system to

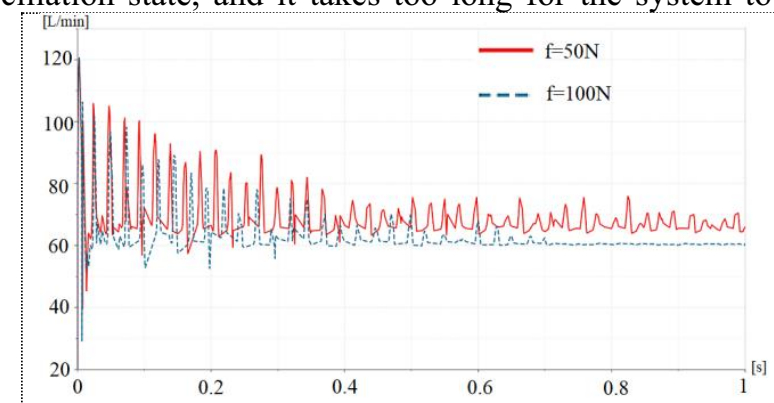

(a)When preload value is $50 \mathrm{~N}, 100 \mathrm{~N}$ stabilize. In the third stage, the system has strong oscillations and poor stability.

In the second stage, several sets of data can quickly reach stability and the system is relatively stable. It can be found that before these sets of data reach stability, their oscillation frequency is basically the same, and the resulting phase change is due to the gradual increase of time to reach the set preload value. As the preload increases, the time to stabilize is decreasing, but the oscillation shock at the beginning of the simulation is increasing.

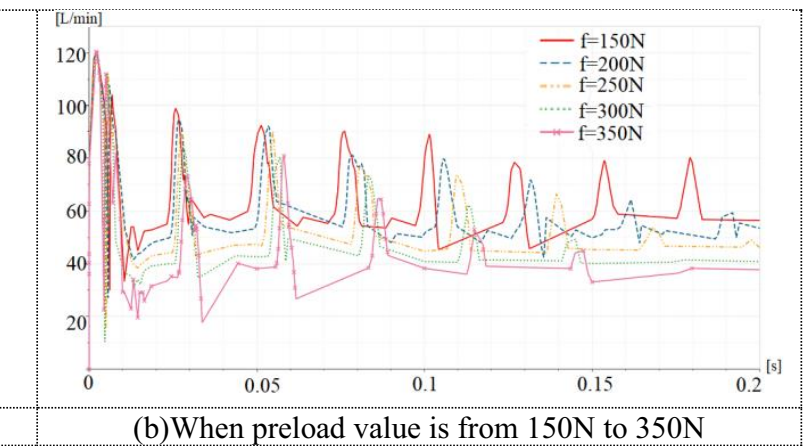




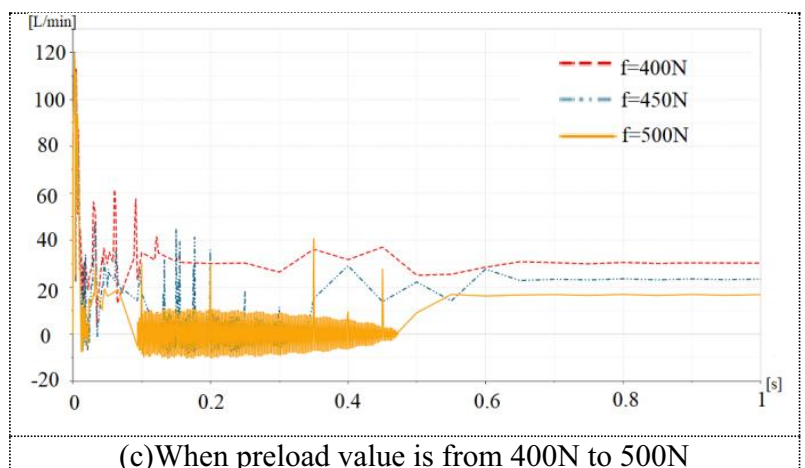

Figure 9. The three stages of the flow rate entering the three-way flow valve.

The above conclusions help people understand the influence of the spring preload of the three-way flow valve on the system, and initially determine the preload value between $150 \mathrm{~N}$ and $350 \mathrm{~N}$. This not only points out the direction of subsequent parameter optimization, but also proves that the system simulation method plays a role in the design of multiway valves.

\section{Conclusions}

In this paper, the following work is carried out:

(1) The control principle and flow distribution characteristics of the electro-hydraulic proportional load-sensitive multiway valve are analyzed from a theoretical perspective.

(2) Then, a visualized mechanical-hydraulic system simulation model is established in AMEsim based on the multiway valve in an excavator. The three-dimensional motion of the excavator can be visualized in parameter or simulation mode, which helps to judge the correctness of the system model and parameters in real time without additional co-simulation. The accuracy of the simulation model is verified by theoretical analysis.

(3) With the design parameters as input, the effect of the design parameters can be determined by the batch processing method in simulation model, which is efficient to guide the design of multiway valve and do the next research.

\section{Acknowledgments}

This research is financially supported by SCU-Zigong Science and Technology Cooperation Special Foundation (No.2019CDZG-5).

\section{References}

1. Wang Q, Zhu C. (2014) Study on Dynamic Characteristics of Hydraulic System of ZYWL-6000D Full Hydraulic Directional Drill. Journal of Vibration \& Shock, 33: 174-179, 188.

2. Yang HY, Cao J, Xu B, et.al. (2015) The Development History and Research Prospect of Multiway Reversing Valve. Chinese. Journal of Mechanical Engineering, (10): 1-5.
3. Wang WP, Zhao JY, Ding HG.(2016) Research on Electro-hydraulic Flow Matching Control. In: The 9th National Conference on Fluid Power Transmission and Control (9th FPTC-2016) Proceedings. Hangzhou. pp. 108-111.

4. Zhang LP,Xu L, Wang XJ, He SQ.(2020) Multi-way valve visualization machine-hydraulic system modeling and dynamic characteristics research. Journal of Drainage and Irrigation Machinery Engineering,38:1037-1044.

5. Zhao PY, Chen YL, Zhou H. (2016) Overview of hydraulic hybrid engineering machinery system and control strategy. Journal of Zhejiang University, 50:449-459.

6. Jiang T, Huang W, Wang AL. (2016) The topological design of multi-way directional valve reversing coupling valve port throttling structure. Journal of Xi'an JiaoTong University, 50: 26-31.

7. Zhang LJ, Wang LH, Wang S, Li DX. (2016) Analysis of the flow area of a slide valve with a channel sink. China Mechanical Engineering, 27: 2437-2442.

8. Yin S, Gong J, Guan T. (2014) Research on Dynamic Characteristics of Multiway Valve LUDV System of Hydraulic Excavator. Computer Simulation, 31:187-191,197

9. Raduenz H, Mendoza YEA, Ferronatto D, et al. (2018) Online fault detection system for proportional hydraulic valves. Journal of the Brazilian Society of Mechanical Sciences \& Engineering, 40:331.

10. Li XD, Chen X, Zhou CS. (2018) Combined Observer-Controller Synthesis for Electro-Hydraulic Servo System with Modeling Uncertainties and Partial State Feedback. Journal of the Franklin Institute.355:5893-5911 